\title{
ELECTROCHEMICAL DETECTION OF SMALL VOLUMES OF GLYPHOSATE WITH MASS-PRODUCED NON-MODIFIED GOLD CHIPS
}

\author{
V. Mizers*, V. Gerbreders, E. Sledevskis, I. Kokina, E. Tamanis, \\ M. Krasovska, I. Mihailova, A. Orugcovs, A. Bulanovs \\ Daugavpils University, 1 Parades Str., Daugavpils, LATVIA \\ *e-mail: pro100vald@gmail.com
}

Mass-produced printed circuit board (PCB) electrodes were used as electrochemical cells to detect the widely-used herbicide glyphosate. Square wave voltammetry (SWV) was used to determine the presence of glyphosate in aqueous $\mathrm{Cu}\left(\mathrm{NO}_{3}\right)_{2}$ solution. Optimal measurement conditions for the detection of glyphosate with PCB electrodes were found. It was determined that glyphosate was able to soak into the growing plants from the substrate. Glyphosatecontaminated plant juice was distinguished from control samples using the PCB electrode. Glyphosate-contaminated plants were found to have DNA mutations.

Keywords: electrochemical, glyphosate, printed circuit board, sensor, square wave voltammetry

\section{INTRODUCTION}

Glyphosate is the widely-used herbicide considered to have low toxicity, and it is widely used in agriculture [1]. However, ingestion of glyphosate leads to a large number of health issues, including respiratory malfunction, altered consciousness, increased cancer risk, and death [2]-[4].

It is necessary to develop reliable glyphosate detection methods since modern laboratories frequently fail to detect glyphosate in food products [5]. Electrochemical methods are widely used to determine various chemical substances present in solutions, ranging from simple ion detection [6] to complex biological molecule detection [7]. Several electrochemical approaches have been developed in the past two decades [8]. Copper electrodes have shown potential for selective detection of glyphosate in liquids [9]-[11]. Several researchers have suggested that glyphosate can form water-soluble complexes with copper ions 
[12]-[13]. Since copper ions by themselves can be detected with electrochemical methods, it is possible to use $\mathrm{Cu}^{2+}$ containing buffer solutions to indirectly detect glyphosate from the change in copper ions electrochemical activity.

Since glyphosate is a widely-used herbicide, it is necessary to develop an easyto-use and cheap method for controlling glyphosate levels at farming sites. An easily available approach for electrode mass production is printed circuit boards (PCBs) since they can be produced at factories throughout the world in large quantities for low cost, and most of the factories can offer electrode-surface coating with gold, making them chemically neutral. PCB electrodes can also be suitable for small liquid volumes, making it possible to run an electrochemical analysis of a $10-\mu \mathrm{L}$ drop. This greatly reduces the number of the necessary sample preparation steps and the amount of chemicals used in the analysis. There is no need for electrode-surface modification since glyphosate can be detected indirectly by electrochemical quantification of $\mathrm{Cu}^{2+}$ ions. In this paper, PCB gold-coated electrodes were used to indirectly detect glyphosate in solution using the described method.

\section{EXPERIMENTAL}

\subsection{Reagents and Materials}

Reagents used in the research were the following: copper nitrate trihydrate $(99.9 \%$ pure, purchased from Lach-Ner), commer-

\subsection{Mass-Produced Au Chip}

In place of an electrochemical cell, a mass-produced PCB chip was used. The working area of the chip consisted of 8 copper electrodes covered in gold via the ENIG process, on an FR-4 glass-reinforced epoxy laminate. Each of the electrodes had an individual copper track connected to it, allowing for versatile electrode configuration. All tracks were covered in a protective cial glyphosate-based herbicide (containing $360 \mathrm{~g} / \mathrm{L}$ of glyphosate izopropylamine), $97 \%$ ethanol, and distilled water.

dielectric polymer. The final product can be seen in Fig. 1. The electrodes were designed to each have a rectangular-shaped $150 \mathrm{x}$ $125-\mu \mathrm{m}$ exposed gold-covered area. The electrochemical measurements were made using a Zanher Zennium Electrochemical Workstation in square wave voltammetry (SWV) mode, using chip as a three-electrode electrochemical cell.
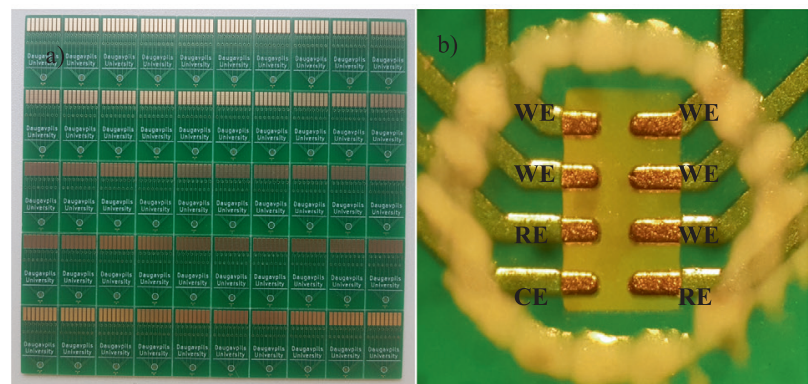

Fig. 1. a) Mass-produced PCB chips with Au-coated electrodes. b) Chip electrode configuration. WE=working electrode, $\mathrm{CE}=$ counter electrode, and $\mathrm{RE}=$ reference electrode. The diameter of the white ring is $1 \mathrm{~mm}$. 


\subsection{Sample Preparation}

Prior to electrochemical measurements, PCB chips were washed in ethanol and cleaned with a nitrogen jet to free the working surface of any production-process residue. In the first experiment, commercial glyphosate was mixed in copper nitrate buffer to the desired concentration. Then, after a delay of 30 minutes, $10 \mu \mathrm{L}$ drops of the resulting solution were placed on the chip working-area and measured via SWV. A new chip was used for each separate drop; however, all used chips were from the same

\subsection{Molecular Studies}

Genomic DNA was extracted from samples $(n=60)$ of fresh, 7-day-old rye plant seedlings treated with $1 / 10$ of the working concentration of glyphosate $(n=30)$ and without it $(\mathrm{n}=30)$. Extraction was done with slight modification using the purification of total DNA from plant tissue Mini Protocol (DNeasy Plant Mini Kit, Qiagen GmbH, Hilden, Germany). The genomic DNA was quantified using a spectrophotometer (NanoDrop 1000, Thermo Scientific, Waltham, the USA) to measure absorbance at $260 \mathrm{~nm}$, and the purity of the DNA was determined. Stock DNA was diluted to make a working solution of $50 \mathrm{ng} / \mu \mathrm{L}$ for further PCR analysis. batch. In the second experiment, plant juice was extracted by crushing plant tissue and filtering the resulting mass through coarse mesh. The extracted juice was then mixed with copper nitrate buffer, centrifuged after a 30-minute delay, and the resulting solution was separated from the solid residue. This solution was then placed on the chip working area in $10-\mu \mathrm{L}$ drops and measured via SWV.

Five random amplified polymorphic DNA (RAPD) primers, OPA-02, OPA-07, OPA-11, OPD-18, and OPN-15 (Table 1), were selected for the study. PCR reactions were carried out in a thermocycler (Veriti 96-WellThermal Cycler, Applied Biosystems, Foster City, the USA). All PCR reactions were prepared as described in [14]. RAPD fragments were separated, and the product length was detected using the QIAxcel (Qiagen GmbH, Hilden, Germany) capillary automated electrophoresis system. The amplification reaction for each primer was repeated twice for each sample to ensure reproducibility. Only clear and reproducible bands were considered for the analysis.

Table 1. Sequences of the 10-mer Primers (5'-3') Used in the Experiments

\begin{tabular}{|l|c|}
\hline Primer ID & Sequence (5'-3') \\
\hline OPA-02 & 5'- TGCCGAGCTG-3' \\
\hline OPA-07 & 5'-GAAACGGGTG-3' \\
\hline OPA-11 & 5'-CAATCGCCGT-3' \\
\hline OPD-18 & 5'-GAGAGCCAAC-3' \\
\hline OPN-15 & 5'-CAGCGACTGT-3' \\
\hline
\end{tabular}




\subsection{Glyphosate Detection in Copper Nitrate Buffer Solution}

Due to the extremely small electrode surface area (approximately $1.88 \times 10^{-8} \mathrm{~m}^{2}$ for a single electrode), to obtain significant current through the cell, a buffer with relatively high copper nitrate concentration is required. However, higher copper nitrate concentration leads to a higher glyphosate detection threshold since a less relative change in $\mathrm{Cu}^{2+}$ ion concentration is induced by the same glyphosate concentration. The optimal buffer was determined to be a 15 $\mathrm{mmol} / \mathrm{L} \mathrm{Cu}\left(\mathrm{NO}_{3}\right)_{2}$ solution in deionized water.

The SWV results for the detection of glyphosate in $15 \mathrm{mmol} / \mathrm{L} \mathrm{Cu}\left(\mathrm{NO}_{3}\right)_{2}$ buffer can be seen in Fig. 2. It should be noted that the current was normalised to the maximum current value. As the measurements have shown, the maximum-current peakamplitude corresponds to the $0 \mathrm{mmol} / \mathrm{L}$ glyphosate control solution. The potential

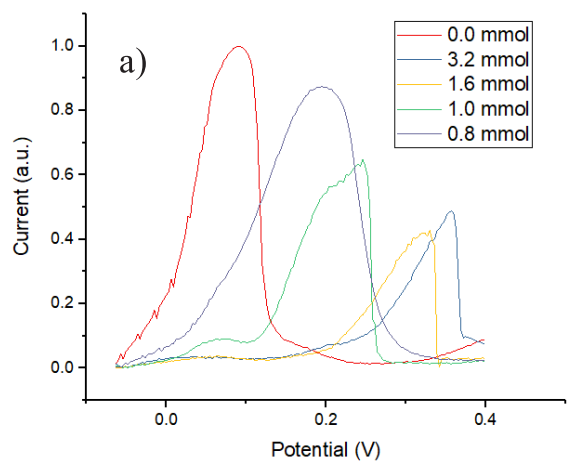

of the main peak from the SWV curve drifts with changes in glyphosate concentration. This could be caused by the change in the $\mathrm{pH}$ value of the solution, as the glyphosate is acidic, and measurements are done in a non-controlled $\mathrm{pH}$ environment. The peak at $50-300 \mathrm{mV}$ is reported to be caused by the reduction of $\mathrm{Cu}^{2+}$ ions [9], and it is easy to notice since this peak has the biggest amplitude. Figure $2 \mathrm{~b}$ shows the main peak amplitude versus glyphosate concentration. In the $0-1.5 \mathrm{mmol} / \mathrm{L}$ range, the peak amplitude drops linearly as the concentration increases and the cell becomes saturated. There is no change in the peak amplitude for concentrations greater than $1.5 \mathrm{mmol} / \mathrm{L}$. This behaviour is approximated by the line in Fig. 2b. The reduction in the main-peak amplitude can be explained by passivation of the electrode surface by the glyphosate/ $\mathrm{Cu}^{2+}$ complex [9].

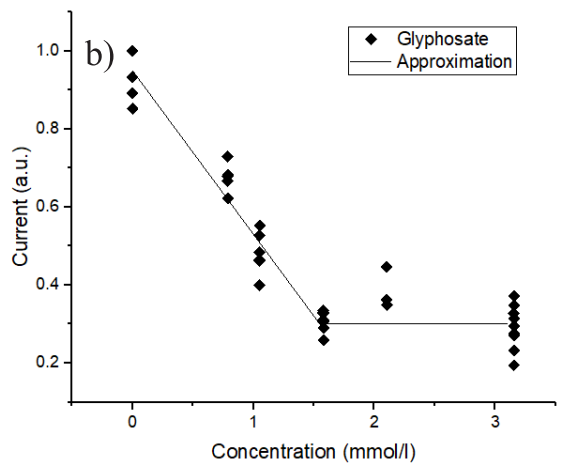

Fig. 2. a) The square wave voltammetry (SWV) results for the detection of glyphosate in copper nitrate solution. b) The main-peak maximum from SWV versus glyphosate concentration. The potential was measured relative to the on-chip Au reference electrode.

\subsection{Glyphosate Detection in Grown Plants}

Rye, wheat, and barley plants were grown to 6-cm long grass, then treated with a 1:10 dose of glyphosate and allowed to grow for additional 5 days. Plant juice was collected and mixed with a small amount of highly-concentrated copper nitrate buf- 
fer to achieve $15 \mathrm{mmol} / \mathrm{L}$ resulting copper nitrate concentration in the solution. The SWV measurement results of the samples can be seen in Fig. 3. The control plant juice did not change the SWV curve shape, and the SWV curve for the control plants with no glyphosate treatment was similar to the curve obtained from copper nitrate solution in deionized water. However, plants that underwent glyphosate treatment showed a slight reduction in the main-peak amplitude of the SWV curve. As can be seen from Fig. $3 b$, samples from the control and glyphosate groups formed two distinct distribution clouds. It is possible to distinguish glyphosate-containing plant juice since the main peak value is less than 0.9 a.u.
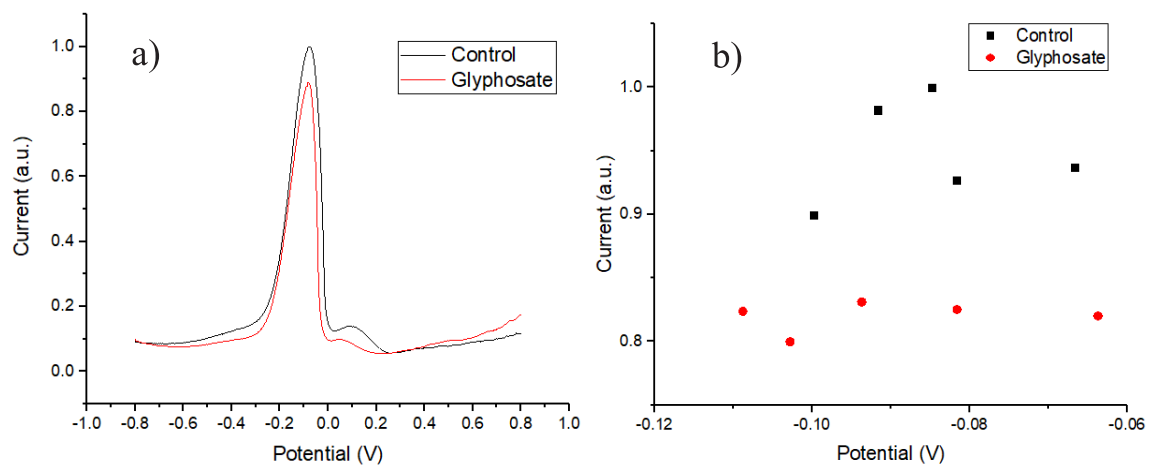

Fig. 3. a) Averaged SWV curve for rye samples.

b) The main-peak potential and current for rye samples.

\subsection{Molecular Studies}

The RAPD technique, a PCR-based technique, has been shown to successfully detect genotoxicity from DNA in plants [15]-[17]. RAPD analysis is capable of detecting temporary DNA changes and is considered more sensitive than classic genotoxic tests, i.e., the comet or micronucleus assay [18]. Moreover, RAPD profiling is successfully used for evaluating the genetic effects of glyphosate on plants [19], [20]. The evident changes observed in the RAPD profiles, such as disappearance and/ or appearance of bands in comparison with untreated control samples, were evaluated and considered to be genotoxic changes. Treatment of rye plant seedlings with $1 / 10$ of the working concentration of glyphosate for 5 days resulted in changes in the RAPD profiles obtained from the exposed plants. RAPD profiles of the plants showed the disappearance of a normal band and the appearance of a new band in comparison with the control. Differences in the DNA banding pattern between control samples and samples treated with glyphosate were significant and were detected at different places with all utilized primers. All obtained DNA bands were polymorphic. The RAPD profiles obtained from the five oligonucleotide primers are presented in Table 2 .

In total, among all primers in the control samples, 27 fragments were detected. Samples treated with glyphosate showed 15 new bands, and 12 bands were eliminated in comparison with the samples without treatment. According to the literature, the disappearance of normal bands can probably be designated as DNA damage through modified bases, point and deletion mutations, and single and double strand breaks, whereas 
new bands generally reveal a change in some oligonucleotide priming sites due to mutations, large deletion, and/or homologous recombination [18], [21], [22]. Over- all, the RAPD results indicate that $1 / 10$ of the working concentration of glyphosate caused significant changes in the genome of the rye plant seedlings.

Table 2. RAPD Profiles from Rye Plant Seedlings without Treatment (Control) and Treated with Glyphosate

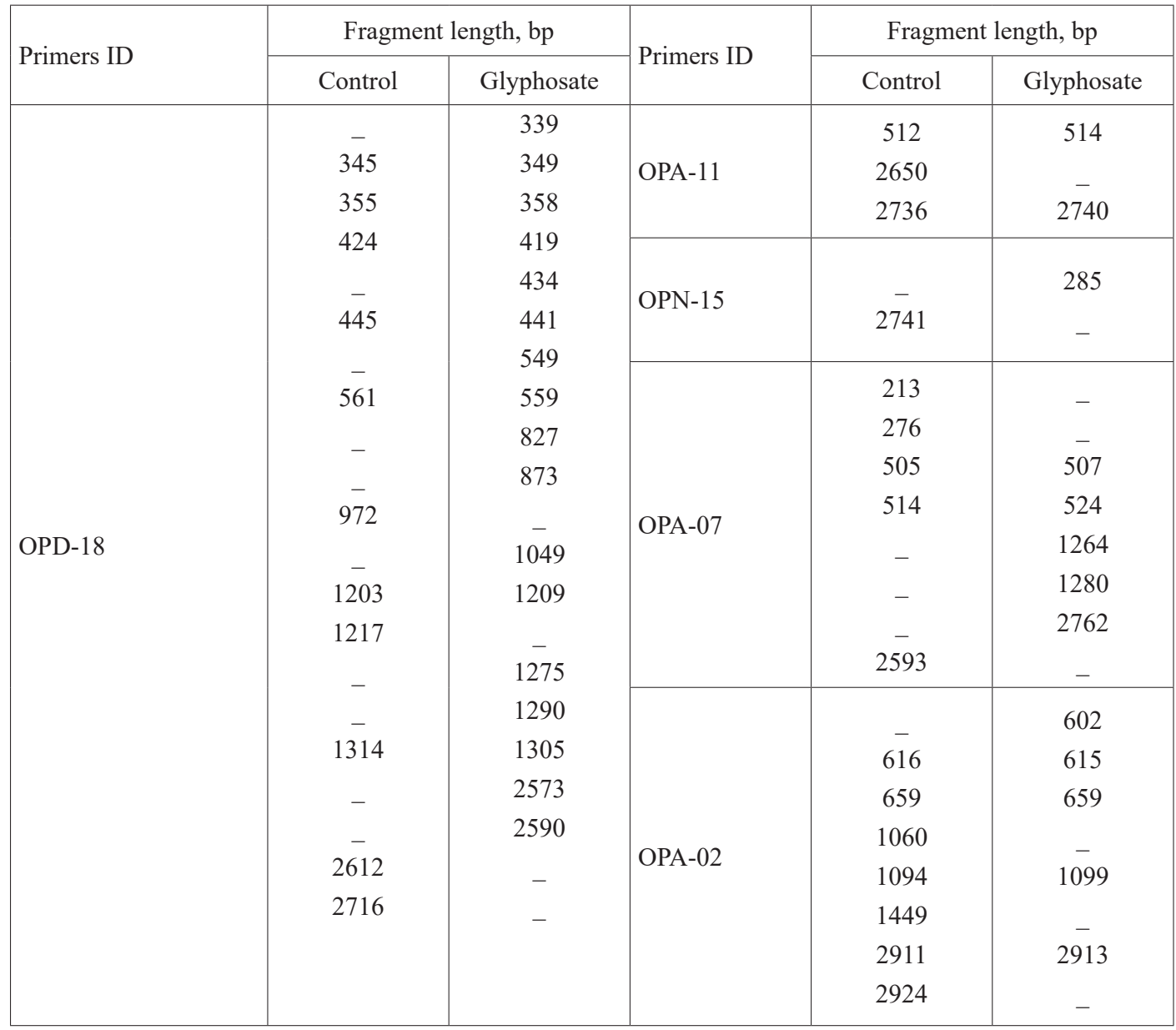

\section{CONCLUSION}

Glyphosate can be successfully detected in both distilled water and plant juice indirectly by adding a $\mathrm{Cu}^{2+}$ ion source to the solution and detecting changes in ion electrochemical activity. Glyphosate presence in plant juice was also confirmed by investigation of the plant DNA. The described method provides a fast and cheap way to control glyphosate usage in the field. Since
PCB electrodes are easy to mass produce, electrochemical analysis can be done in a mobile lab, and required chemicals are common. Due to consistent reduction in the main peak amplitude from the SWV, glyphosate-contaminated samples can be easily distinguished from non-contaminated samples, and the glyphosate tests can be automated. 
1. Stephen, D. O., \& Stephen, P. B. (2008). Glyphosate: AOnce-in-a-Century herbicide. Society of Chemical Industry. doi:10.1002/ ps. 1518

2. Linglee, H., Wenchen, K., Hsienchi, C., Jonghuang, J., \& Miintsai, L. (2000). Clinical Presentations and Prognostic Factors of a Glyphosate-Surfactant Herbicide Intoxication: A Review of 131 Cases. Academic Emergency Medicine, 7(8), 906-910. doi:10.1111/j.1553-2712.2000. tb02069.x

3. Roberts, D. M., Buckley, N. A., \& Mohamed, F. (201). Acute Self-Poisoning with Glyphosate Herbicide: A Prospective Observational Study of the Clinical Toxicology of Glyphosate-Containing Herbicides in Adults with Acute SelfPoisoning. Clinical Toxicology, 48, 129136. doi:10.3109/15563650903476491

4. Shim, Y. K., Steven, M. P., \& Wijngaarden, E. (2009). Parental Exposure to Pesticides and Childhood Brain Cancer: U.S. Atlantic Coast Childhood Brain Cancer Study. Environmental Health Perspectives, 117(6), 1002-1006. doi:10.1289/ehp.0800209

5. Simonetti, E., Cartaud, G., Quinn, R. M., \& Dinelli, I. M. (2015). An Interlaboratory Comparative Study on the Quantitative Determination of Glyphosate at Low Levels in Wheat Flour. Journal of AOAC International, 98 (6), 1760-1768. doi:10.5740/jaoacint.15-024

6. Krasovska, M., Gerbreders, V., Mihailova, I., Ogurcovs, A., Sledevskis, E., Gerbreders, A., \& Sarajevs, P. (2018). ZnO-Nanostructure-Based Electrochemical Sensor: Effect of Nanostructure Morphology on the Sensing of Heavy Metal Ions. Beilstein Journal of Nanotechnology, 9, 2421-2431. doi:10.3762/bjnano.9.227

7. Gerbreders, V., Krasovska, M., Mihailova, I., Ogurcovs, A., Sledevskis, E., Gerbreders, A., \& Plaksenkova, I. (2019). ZnO Nanostructure-Based Electrochemical Biosensor for Trichinella DNA Detection.
Sensing and Bio-Sensing Research, 23. doi:10.1016/j.sbsr.2019.100276

8. Valle, A. L. (2018). Glyphosate Detection: Methods, Needs and Challenges. Environmental Chemistry Letters. doi:10.1007/s10311-018-0789-5

9. Aguirre, M. C., Urreta, S. E., \& Gomez, C. G. (2018). A Cu2+-Cu/Glassy Carbon System for Glyphosate Determination. Sensors and Actuators B: Chemical, 284, 675-683. doi:10.1016/j.snb.2018.12.124

10. Moraes, F., Mascaro, L., Machado, S., \& Brett, C. (2010). Direct Electrochemical Determination of Glyphosate at Copper Phthalocyanine/Multiwalled Carbon Nanotube Film Electrodes. Electroanalysis, 22 (14), 1586-1591. doi:10.1002/ elan.200900614

11. Pintado, S., Amaro, R. R., Mayén, M., \& Mellado, J. M. (2012). Electrochemical Determination of the Glyphosate Metabolite Aminomethylphosphonic Acid (AMPA) in Drinking Waters with an Electrodeposited Copper Electrode. International Journal of Eelectrochemical Science, 7, 305-312.

12. Coutinho, C., Silva, M., Machado, S., \& Mazo, L. (2007). Influence of Glyphosate on the Copper Dissolution in Phosphate Buffer. Applied Surface Science, 253, 3270-3275. doi:10.1016/j.apsusc.2006.07.020

13. Coutinho, C., Silva, M., Calegaro, M., Machado, S., \& Mazo, L. (2007). Investigation of Copper Dissolution in the Presence of Glyphosate Using Hydrodynamic Voltammetry and Chronoamperometry. Solid State Ionics, 178, 161-164. doi:10.1016/j. ssi.2006.10.027

14. Kokina, I., Jahundoviča, I., Mickeviča, I., Sledevskis, E., Ogurcovs, A., \& Polyakov, B. (2015). The Impact of CdS Nanoparticles on Ploidy and DNA Damage of Rucola (Eruca sativa Mill.) Plants. Journal of Nanomaterials. Article ID 470250. doi:10.1155/2015/470250 
15. Moreno-Olivas, F., Jr., V. U. Gant Jr., Johnson, K. L., Peralta-Videa, J. R., \& Gardea-Torresdey, J. L. (2014). Random Amplified Polymorphic DNA Reveals that $\mathrm{TiO} 2$ Nanoparticles are Genotoxic to Cucurbita Pepo. Journal of Zhejiang University: Science A, 15, 618-623. doi:10.1631/jzus.A1400159

16. Bhaduri, A. M., \& Fulekar, M. H. (2015). Biochemical and RAPD Analysis of Hibiscus rosa sinensis Induced by Heavy Metals. Soil and Sediment Contamination: An International Journal, 411-422. doi:10 $.1080 / 15320383.2015 .970683$

17. Sorrentino, M. C., Capozzi, F., Giordano, S., \& Spagnuolo, V. (2017). Genotoxic Effect of $\mathrm{Pb}$ and $\mathrm{Cd}$ on in Vitro Cultures of Sphagnum Palustre: An Evaluation by ISSR Markers. Chemosphere, 208-215. doi:10.1016/j.chemosphere.2017.04.065

18. Pandey, C., \& Gupta, M. (2015). Selenium and Auxin Mitigates Arsenic Stress in Rice (Oryza sativa L.) by Combining the Role of Stress Indicators, Modulators and Genotoxicity Assay. Journal of Hazardous Materials, 384-391. doi:10.1016/j. jhazmat.2015.01.044

19. Nardemir, G., Agar, G., Arslan, E., \& Erturk, F. A. (2015). Determination of Genetic and Epigenetic Effects of Glyphosate on Triticum Aestivum with RAPD and CRED-RA Techniques. Theoretical and Experimental Plant Physiology, 131-139. doi:10.1007/s40626-015-0039-1
20. Silprasit, K., Ngamniyom, A., Kerksakul, P., \& Thumajitsakul, S. (2016). Using Morphology and Genomic Template Stability (GTS) to Track Herbicide Effect on Some Submersed Aquatic Plants. Applied Environmental Research, 75-85. doi:10.35762/AER.2016.38.1.7

21. Ackova, D. G., Kadifkova-Panovska, T., Andonovska, K. B., \& Stafilov, T. (2016). Evaluation of GENOTOXIC VARIATIONS in PLANT MODEL SYSTEMS in a CASE of METAL STRESSORS. Journal of Environmental Science and Health, Part B: Pesticides, Food Contaminants, and Agricultural Wastes, 340-349. doi:10.1080/ 03601234.2015.1128747

22. Venkatachalam, P., Jayalakshmi, N., \& Geetha, N. (2017). Accumulation Efficiency, Genotoxicity and Antioxidant Defense Mechanisms in Medicinal Plant Acalypha Indica L. under Lead Stress. Chemosphere, 544-553. doi:10.1016/j. chemosphere.2016.12.092 